\title{
Super-capacitor Integration into Hybrid Vehicle Power Source
}

\author{
V. Bršlica \\ Department of Electrical Engineering \\ University of Defence in Brno \\ Kounicova 65, 61200 Brno (Czech republic) \\ Phone/Fax number:+ 420973 442319/443773, e-mail: vit.brslica@unob.cz
}

\begin{abstract}
The plug-in hybrid vehicle based on the concept of battery operated vehicle with strong electrical motor(s) and electrochemical battery is for thermal comfort of crew and for occasional elongated travel range completed by generator, which is designed on average traction power only and during of journey is mainly used in co-generative run for cabin heating. Such vehicle efficiency can be improved by the third power source, specifically used only for acceleration and regenerative braking purposes. That role is optimal for super-capacitor, which has very good charging efficiency and can store the energy from braking to the next acceleration. Both these actions are usually very fast with high power in very short time. Its sizing and voltage control is investigated in this paper.
\end{abstract}

\section{Key words}

Fuel save, hybrid vehicle, super-capacitor, power control, multi source supply

\section{Introduction}

The typical hybrid electrical vehicles (HEV), which are in last few years offered on the market, are the first and the most expensive models for richest clients, with extremely high power. Their concept is based on the strong and great engine supported by relatively weaker electrical motor, which is used only at low speed range, where it assists to engine to reach better dynamics and faster acceleration. Moreover its role is in replacing the starter, which cannot be so frequently used, and in the motor run it helps by the numerous engine starts to eliminate idle run losses in the urban traffic. Such concept brings evident fuel save, but the fuel consumption is less then $30 \%$ reduced, comparing to classical vehicle without hybrid drive, but only in citycycle. Typical representatives are Toyota Prius and Honda Civic Hybrid [1] - [3].

The different approach to the hybrid vehicle concept is used in the new category of plug-in hybrids, represented by the American prototype car Chevrolet Volt [4], [5], which is primarily declared as battery operated electric vehicle (BEV) that is driven by energy from house plug stored during the night for short commute. Only in the case of occasional longer trip the drive is supplied simultaneously from onboard generator, but this operational range extension is paid by much higher fuel consumption. Internal combustion engine (ICE) driving the generator delivers in cogeneration the thermal energy for cabin heating, with minimal fuel consumption in idle run [6], [7]. The operating range $60 \mathrm{~km}$ does not need too big battery but no only the battery mass is reduced, also the battery power.

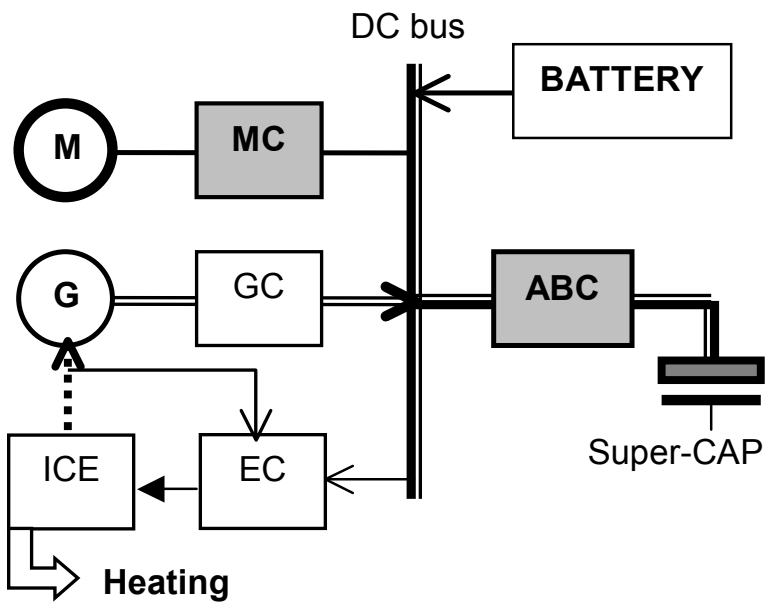

Fig.1. Schematic 3 power sources cooperation in HEV

The typical battery property is very limited peak of power and also the capacity decrease with growing load. Moreover the great load causes, due to big current, the thermal losses increase, which can damage the battery. If the battery load is limited the vehicle acceleration is small and such vehicle appears not enough dynamic in modern traffic. To conform the power source to the driving motor dynamics, the third power source should be introduced (Fig.1) with minimal internal resistance and without time delay between the charge and recharge process, which exists in any electro-chemical battery. From this point of view the capacitor use is optimal, 
although its voltage is not constant. Such conception is presented in Fig. 1 where the components are:

$\mathrm{M} \quad$ electric motor(s) for vehicle drive

$\mathrm{MC}$ motor power control

ICE internal combustion engine

$\mathrm{G}$ generator driven by ICE

GC generator power controller

EC ICE throttle control

$\mathrm{ABC}$ acceleration \& braking power control

If the acceleration power is delivered from generator $G$, the energy from braking must be wasted in the resistor as a thermal energy, or partially can be recuperated into electrochemical battery (at slow deceleration).

The architecture of the control loop over all presented control units is not the target of this paper, as well as the battery management.

\section{Power and Energy Calculation}

All the calculations are prepared for the sample project vehicle with total mass $\mathrm{m}=1000 \mathrm{~kg}$ (vehicle curb weight about $600 \mathrm{~kg}$ !) and can be easily transformed to smaller or bigger vehicle, with the same frontal area $\mathrm{S}_{\mathrm{x}}=1,5 \mathrm{~m}^{2}$ and aerodynamic coefficient, which are not principally proportional to the vehicle mass. The traction power is given by formula:

$$
\mathrm{P}=\mathrm{F}_{\mathrm{t}} \mathrm{V}
$$

where $\mathrm{v}[\mathrm{m} / \mathrm{s}]$ is the running speed and $F_{t}[\mathrm{~N}]$ is the traction force on the wheels circumference. This force can be divided at least in four components:

$$
\mathrm{F}_{\mathrm{t}}=\mathrm{F}_{\mathrm{r}}+\mathrm{F}_{\mathrm{w}}+\mathrm{F}_{\mathrm{c}}+\mathrm{F}_{\mathrm{a}}
$$

which are more detailed described and studied in the next.

\section{A. Constant Speed Horizontal Run}

To keep the vehicle at constant speed on the horizontal plane supposes, that two forces must be compensated the rolling resistance force $F_{r}$ and the aerodynamic one $\mathrm{F}_{\mathrm{w}}$. The first one depends on the rolling friction factor $\mathrm{k}_{\mathrm{r}}$ and can be described by formula:

$$
\mathrm{F}_{\mathrm{r}}=\mathrm{k}_{\mathrm{r}} \mathrm{G}
$$

Where $\mathrm{G}[\mathrm{N}]$ is the gravitational force dependent on the vehicle mass $\mathrm{m}$, and acceleration of gravity $\mathrm{g}=9,81 \mathrm{~m} \mathrm{~s}^{-2}$ :

$$
\mathrm{G}=\mathrm{mg}
$$

The aerodynamic resistance force depends on the frontal cross-sectional area of car Sx $\left[\mathrm{m}^{-2}\right]$, its shape, which can be described by aerodynamic coefficient $\mathrm{Cx}$ and moreover is this force speed dependent according to formula:

$$
\mathrm{F}_{\mathrm{w}}=\gamma \mathrm{C}_{\mathrm{x}} \mathrm{S}_{\mathrm{x}} \mathrm{v}^{2}
$$

Where the $\gamma$ is the air density value, which is dependent on the humidity, temperature and the elevation above sea level, but it can be assumed approximately $\gamma=1,2 \mathrm{kgm}^{-3}$. The modern car bodies reach the $C_{x}=0,30$ very easily. The survey of steady-state power for important speed range, supposing the rolling friction coefficient $\mathrm{k}_{\mathrm{r}}=0,02$, is in Table I.

TABLE I. - Traction power [W] in components

\begin{tabular}{|r|r|r|r|r|}
\hline $\mathrm{km} / \mathrm{h}$ & $\mathrm{m} / \mathrm{s}$ & \multicolumn{1}{|c|}{ P roll } & \multicolumn{1}{|c|}{ P wind } & \multicolumn{1}{c|}{ P sts } \\
\hline $\mathbf{2 0}$ & 5,6 & 1111 & 46 & $\mathbf{1 1 5 7}$ \\
\hline $\mathbf{4 0}$ & 11,1 & 2222 & 370 & $\mathbf{2 5 9 3}$ \\
\hline $\mathbf{6 0}$ & 16,7 & 3333 & 1250 & $\mathbf{4 5 8 3}$ \\
\hline $\mathbf{8 0}$ & 22,2 & 4444 & 2963 & $\mathbf{7 4 0 7}$ \\
\hline $\mathbf{1 0 0}$ & 27,8 & 5556 & 5787 & $\mathbf{1 1 3 4 3}$ \\
\hline $\mathbf{1 2 0}$ & 33,3 & 6667 & 10000 & $\mathbf{1 6 ~ 6 6 7}$ \\
\hline
\end{tabular}

\section{B. Up-grade Run}

The uphill run increase the potential energy, stored in the vehicle, which must be supplied from the power source. The uphill gradient $\mathrm{H} / \mathrm{L}$ does not usually increase $12 \%$ (16\% on local road) and it is equal to sine of gradient angle $\alpha\left[^{\circ}\right]$ by formula:

$$
\sin \alpha=\mathrm{H} / \mathrm{L}
$$

Where $\mathrm{L}$ is for the length of route and $\mathrm{H}$ is for the ascended height. This traction force component $F_{c}$ can be described by formula:

$$
\mathrm{F}_{\mathrm{c}}=\mathrm{G} \sin \alpha
$$

The power for fast uphill run is often the biggest component of all traction forces. Oppositely the low power results in slow speed in the slope according to (1) and retardation to other transport (typical for heavy trucks with low power to mass ratio).

TABLE II. - Traction power Pup [W] increase in grades

\begin{tabular}{|r|r|r|r|r|r|}
\hline $\mathrm{km} / \mathrm{h}$ & $\mathrm{m} / \mathrm{s}$ & $4 \%$ & $8 \%$ & $12 \%$ & $16 \%$ \\
\hline $\mathbf{2 0}$ & 5,6 & 2222 & 4444 & 6667 & 8889 \\
\hline $\mathbf{4 0}$ & 11,1 & 4444 & 8889 & 13333 & 17778 \\
\hline $\mathbf{6 0}$ & 16,7 & 6667 & 13333 & $\mathbf{2 0} \mathbf{0 0 0}$ & 26667 \\
\hline $\mathbf{8 0}$ & 22,2 & 8889 & 17778 & 26667 & 35556 \\
\hline $\mathbf{1 0 0}$ & 27,8 & 11111 & 22222 & 33333 & 44444 \\
\hline $\mathbf{1 2 0}$ & 33,3 & 13333 & 26667 & 40000 & 53333 \\
\hline
\end{tabular}

For any speed from Table II must be added the basic power from Table I. The power $40 \mathrm{~kW}$ for $1000 \mathrm{~kg}$ is acceptable in majority of cars to keep the constant speed $90 \mathrm{~km} / \mathrm{h}$ in the $12 \%$ slope and $110 \mathrm{~km} / \mathrm{h}$ in the $8 \%$ grade.

\section{Acceleration and Dynamic Braking}

Power reserve in the acceleration improves the dynamics and shorten the acceleration distance, oppositely if the driving motor in braking run can be highly loaded as a generator, the mechanical brakes should not be used and the potential energy can be changed back to the electrical one for the next acceleration. The acceleration force $F_{a}$ can be described as follow:

$$
\mathrm{F}_{\mathrm{a}}=\mathrm{a} \mathrm{m}
$$


where $\mathrm{a}\left[\mathrm{m} \mathrm{s}^{-2}\right]$ is for acceleration.

The survey of time and distance together with power and energy can be observed in Table III for 3 different acceleration values.

TABLE III. - Various accelerations power and distance

\begin{tabular}{|r|r|r|r|r|}
\hline \multicolumn{4}{|c|}{$\mathrm{a}=1$} & $\mathrm{~F}_{\mathrm{a}}=1000 \mathrm{~N}$ \\
\hline $\mathrm{t}[\mathrm{s}]$ & $\mathrm{v}[\mathrm{m} / \mathrm{s}]$ & $\mathrm{Pa}[\mathrm{W}]$ & Energy [J] & Dist [m] \\
\hline 10 & 10 & 10000 & 50000 & 50 \\
\hline 15 & 15 & $\mathbf{1 5 0 0 0}$ & 112500 & 112,5 \\
\hline 24 & 24 & 24000 & 288000 & 288 \\
\hline
\end{tabular}

\begin{tabular}{|r|r|r|r|r|}
\hline \multicolumn{4}{|c|}{$\mathrm{a}=3$} & $\mathrm{~F}_{\mathrm{a}}=3000 \mathrm{~N}$ \\
\hline 1 & 3 & 9000 & 4500 & 1,5 \\
\hline 5 & 15 & $\mathbf{4 5 0 0 0}$ & 112500 & 37,5 \\
\hline 8 & 24 & 72000 & 288000 & 96 \\
\hline
\end{tabular}

\begin{tabular}{|r|r|r|r|r|}
\hline \multicolumn{4}{|c|}{$\mathrm{a}=5$} & $\mathrm{~F}_{\mathrm{a}}=5000 \mathrm{~N}$ \\
\hline 1 & 5 & 25000 & 12500 & 2,5 \\
\hline 3 & 15 & $\mathbf{7 5 0 0 0}$ & 112500 & 22,5 \\
\hline 5 & 25 & 125000 & 312500 & 62,5 \\
\hline
\end{tabular}

From the basic mechanics the time of acceleration can be calculated from:

$$
\mathrm{t}=\mathrm{v} / \mathrm{a}
$$

The power $\mathrm{P}$ is calculated according to (1) and the energy is simply:

$$
\mathrm{E}=\int P(t) d t
$$

The supplied energy is mostly stored as the kinetic energy of the vehicle, which depends on the mass and velocity square. The energy calculation is given by formula:

$$
\mathrm{E}=1 / 2 \mathrm{~m} \mathrm{v}^{2}
$$

This energy must be fed into the moving vehicle during the acceleration and can be gained back during the braking.

\section{Super-capacitor vs. Accumulator}

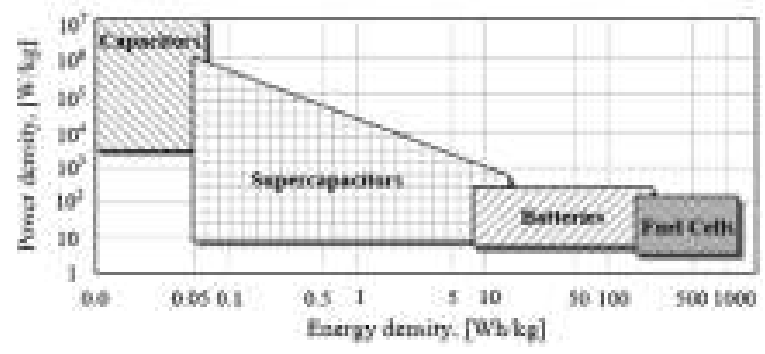

Fig.2. Typical energy stores parameters

The Super-capacitor (SC) energy density is much lower than the same parameter of any electrochemical battery (Table IV), but its power density is oppositely much higher (Table V) [8]. The SC are also known as UltraCapacitors and the comparing survey of both parameters is in Fig.2 for the present day market offer. The SC producers (Maxwell, ELIT, ESMA, Okamura, NessCap, EKOND) technology is based on the EDLC (electrolyte double-layer capacitor) with very low cell-voltage that does not exceed $3 \mathrm{~V}$. Therefore the serial connection of cells into the battery must be realised with all the problems with unequal voltage distribution and cell management circuits.

TABLE IV. - The comparison of super-caps and accumulators

\begin{tabular}{|c|r|r|r|c|r|r|r|}
\hline & & & price & energy & & & \\
\hline & \multicolumn{1}{|c|}{ V } & & EUR & Joule & Wh & Wh/kg & $\mathrm{kg}$ \\
\hline Pb & 24 & $12 \mathrm{Ah}$ & 47 & 1036800 & 288 & 32 & 9,0 \\
\hline LiIon & 28 & $4 \mathrm{Ah}$ & 130 & 403200 & 112 & 140 & 0,8 \\
\hline LiIon & 280 & $4 \mathrm{Ah}$ & 1304 & 4032000 & 112 & 140 & 8,0 \\
\hline SC & 48 & $80 \mathrm{~F}$ & 1381 & 92160 & 25,6 & 2,48 & 10,3 \\
\hline
\end{tabular}

TABLE V. - Super-capacitor 48V block parameters

\begin{tabular}{|r|c|c|c|c|c|c|c|c|}
\hline \multicolumn{1}{|c|}{ C } & E & E & m & P & T & R & RC & price \\
\hline Farad & Joule & Wh & $\mathrm{kg}$ & W & s & m $\Omega$ & s & Eur \\
\hline 80 & 92160 & 25,6 & 10,3 & 42323 & 2,18 & 16 & 1,28 & 1101 \\
\hline 110 & 126720 & 35,2 & 12,1 & 59271 & 2,14 & 12 & 1,32 & 1381 \\
\hline
\end{tabular}

TABLE VI. - SC blocks comparison [10]

\begin{tabular}{|l|c|c|c|c|}
\hline & & $\begin{array}{c}\text { ESMA } \\
30 \text { EC502 }\end{array}$ & $\begin{array}{c}\text { OKAMURA } \\
\text { PMLF54-65 }\end{array}$ & $\begin{array}{c}\text { MAXWELL } \\
\text { BMOD } \\
0115 A V\end{array}$ \\
\hline & & asymmetric & symmetric & symmetric \\
\hline Operating voltage & {$[\mathrm{V}]$} & $22,5-45$ & $0-54$ & $0-42$ \\
\hline Voltage per cell $(\mathrm{vpc})$ & {$[\mathrm{V}]$} & 1,5 & 2,7 & 2,33 \\
\hline Maximal voltage & {$[\mathrm{V}]$} & $51(1,7 \mathrm{vpc})$ & $54(2,7 \mathrm{vpc})$ & $42(2,33 \mathrm{vpc})$ \\
\hline Minimal voltage & {$[\mathrm{V}]$} & 27 & 0 & 0 \\
\hline ESR & {$[\mathrm{m} \Omega]$} & 0,25 & 1,35 & 0,295 \\
\hline Capacitance & {$[\mathrm{F}]$} & 200 & 65 & 145 \\
\hline Stored energy & {$[\mathrm{kJ}]$} & 150 & 90 & 127 \\
\hline Peak current & {$[\mathrm{A}]$} & 2800 & 550 & 600 \\
\hline Mass & {$[\mathrm{kg}]$} & 27 & 6,7 & 16,1 \\
\hline Energy density & {$[\mathrm{J} / \mathrm{kg}]$} & 5,56 & 13,43 & 7,9 \\
\hline Energy density & {$[\mathrm{Wh} / \mathrm{kg}]$} & 1,54 & 3,73 & 2,2 \\
\hline Operating temp. & {$\left[{ }^{\circ} \mathrm{C}\right]$} & $-50-50$ & $-10-40$ & $-40-65$ \\
\hline Storage temp. & {$\left[{ }^{\circ} \mathrm{C}\right]$} & $-60-70$ & $-20-70$ & $-40-85$ \\
\hline Rated life cycle & {$[\mathrm{cycles}]$} & 300000 & $\mathrm{NA}$ & 500000 \\
\hline \multicolumn{5}{|l|}{} \\
\hline \multicolumn{5}{|l|}{}
\end{tabular}

SC have many advantages over traditional electrochemical batteries. Unlike batteries, SC can completely absorb and release a charge at high rates and in a virtually endless cycle with little degradation.

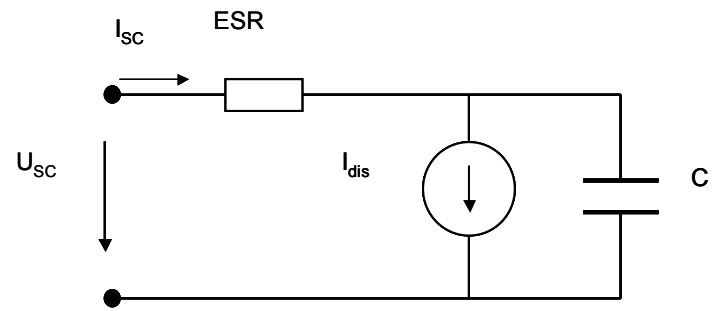

Fig.3. Typical SC equivalent circuit

The electrochemical battery energy is substantially reduced even if the power equals to 1-hour discharge, 
practically all the energy from super-capacitor can be reached in few seconds. The very important parameter is therefore the time constant $\tau=\mathrm{RC}$, which describes the possible speed of discharge.

The highest obtainable power from any voltage source is given by load equal to internal resistance, but the efficiency of such loading is only $50 \%$, that means the same energy as is supplied to the load is dissipated in the internal resistance of the source and there creates the heat. The basic SC equivalent circuit is in Fig. 3 where the self-discharge is modelled by current source, instead of resistor, as is usual in the electrochemical accumulator and here should be said that the output voltage of SC is proportional to the stored charge, that means, it is not constant or quasi constant as in the classical battery. The stored energy is described as:

$$
\mathrm{E}=1 / 2 \mathrm{C} \mathrm{U}^{2}
$$

The exploitable energy depends on the minimal acceptable voltage and can be from the (12) evaluated:

$$
\mathrm{E}_{\mathrm{ex}}=1 / 2 \mathrm{C}\left(\mathrm{U}_{\max }{ }^{2}-\mathrm{U}_{\min }{ }^{2}\right)
$$

Due to square function is the half energy volume removed until the voltage sags down to $70 \%$ Umax and if the voltage falls to $50 \%$ Umax there is only $25 \%$ of the stored energy remained in the SC.

Because of varying SC voltage the SC and the battery must be connected by $\mathrm{DC} / \mathrm{DC}$ converter, typical wiring is in Fig.4, where the bi-directional converter delivers energy in both senses from and back to SC.

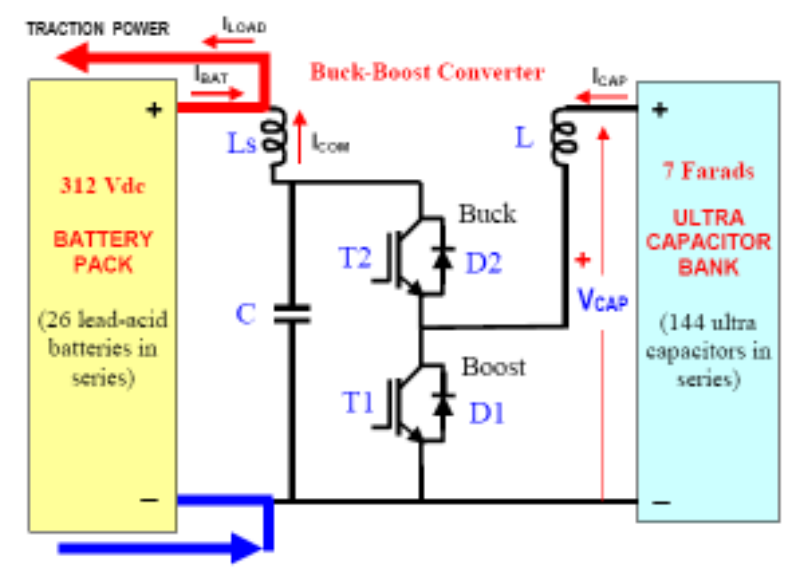

Fig.4. SC connection to the traction battery by Buck-Boost DC/DC Converter

The SC discharge current is described by formula:

$$
\mathrm{I}=\mathrm{C} \frac{d u}{d t}
$$

and the voltage is during the discharge decreasing as follows:

$$
\mathrm{U}=\mathrm{U}_{0}-\frac{1}{C} \int i d t
$$

With decreasing voltage the current must grow up for the constant power, but the power is not constant during the acceleration because the speed grows up and the power too in according with (1). The source or the motor power limitation causes the non-constant acceleration a during all the speed range and when the power limit $\mathrm{P}_{\max }$ is received, the value $F_{a}$ decreases with speed grow-up, so the value a also falls down.

$$
\mathrm{F}_{\mathrm{a}}=\frac{P_{\max }}{v}-\mathrm{F}_{\mathrm{r}}-\mathrm{F}_{\mathrm{w}}(\mathrm{v})-\mathrm{F}_{\mathrm{c}}
$$

Note in the Table IV that in the second row is the Li-Ion battery with ten times lower mass and for equal mass can be obtained four time more energy than from lead acid battery and more than fifty times more energy than from super-cap. From the energy point of view the SC does not contribute very much, but its benefit is evident in the power peaks delivery during the vehicle acceleration and also in dynamic braking without brake and friction-pads wear-out. The enormous number of cycles up to one million predicts this energy storage for the short time power peaks delivery.

\section{Vehicle Dynamics Parameters}

The development in the area of vehicles technology is namely in last years very fast and connected with improved battery parameters as well as pressed by market due to rapid increase of petrol-based fuels. The BEV first generation with manual gear transmission is very historical (1960 - 1990), but e.g. the made-in-France $\mathrm{BEV}$, with NiCd batteries, they are still in the active service, without any power peak source integration. Their dynamics is really very poor if we see their basic parameters in Table VII and the power per $1000 \mathrm{~kg}$ is under $40 \mathrm{~kW}$. But the energy storage is enough for the trips up to $80-150 \mathrm{~km}$.

TABLE VII. - French BEV from PSA production parameters

\begin{tabular}{|c|c|c|c|c|c|c|}
\hline GVW & P/Pmax & & $\mathrm{v} \max$ & Joule & $\mathrm{U}$ & $\mathrm{C}_{5}$ \\
\hline $\mathrm{kg}$ & $\mathrm{kW}$ & & $\mathrm{km} / \mathrm{h}$ & & $\mathrm{V}$ & $\mathrm{Ah}$ \\
\hline 1450 & $15 /$ & $\begin{array}{c}\text { P 106 } \\
\text { C saxo }\end{array}$ & & 43200000 & 120 & 100 \\
\hline 1950 & 28 & $\begin{array}{c}\text { P partner } \\
\text { Berlingo }\end{array}$ & 95 & 58320000 & 162 & 100 \\
\hline
\end{tabular}

Much better dynamics offers new concept of BEV with auxiliary generator $53 \mathrm{~kW}$, which was mentioned above (Chevrolet Volt). Thanks this power support its acceleration is perfect and in the commute up to $60 \mathrm{~km}$ is its fuel consumption only $1,91 / 100 \mathrm{~km}$. With the same energy in battery $(16 \mathrm{kWh})$ it accelerates from 0 to $100 \mathrm{~km} / \mathrm{h}$ in $8,5 \mathrm{~s}$ and its maximal speed is $200 \mathrm{~km} / \mathrm{h}$. Of course it has much stronger motor with rated power $\mathrm{P}_{\mathrm{n}}=$ $40 \mathrm{~kW}$ and maximal power $\mathrm{P}_{\max }=120 \mathrm{~kW}$. The longer trip can be realized with activated generator, and then the fuel consumption 4,9 1/100km appears.

The battery management is very important for any BEV reliable operation and for the battery lifetime. If the battery is permanently charged during the journey it is 
necessary to solve not only the current limitation and the cut off voltage, but also the cooperation of the sources in parallel run.

The reservation of all the capacitor energy only for vehicle acceleration and braking regeneration gives simple rule for the voltage control of the super-capacitor based on the single parameter - vehicle speed. The voltage vs. speed dependence is charted in Fig.5 for the data from Table III (1000kg vehicle with maximal speed $90 \mathrm{~km} / \mathrm{h}$ ) and the necessary capacitor is $20 \mathrm{~F}$. Its mass is $40 \mathrm{~kg}$ as can be found in Table V (four $80 \mathrm{~F} / 48 \mathrm{~V}$ blocks in series).

The capacitor can be reduced more then three times, if the dynamic acceleration only in the city speed limit (50 $\mathrm{km} / \mathrm{h}$ ) is supported, but all these calculations do not take into account the grade up force component $F_{c}$, therefore the first version is better.

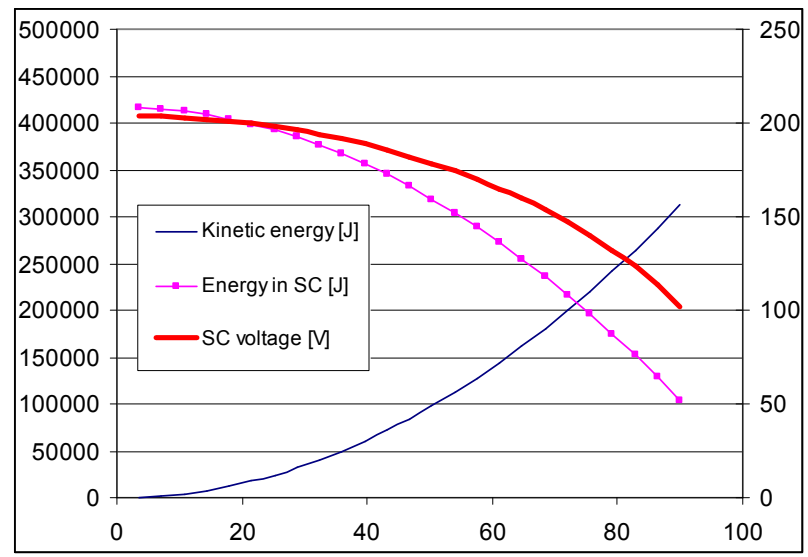

Fig. 5. Voltage and energy in SC vs. speed $[\mathrm{km} / \mathrm{h}]$ for data from Table III

\section{Battery Perspectives}

The situation in the electrical batteries is in the last decade in very fast development, the very powerful LiIon technology is used in notebooks and mobile phones and some new technology is announced every year. One promising product is waited in the March 2008 from Toshiba [13].

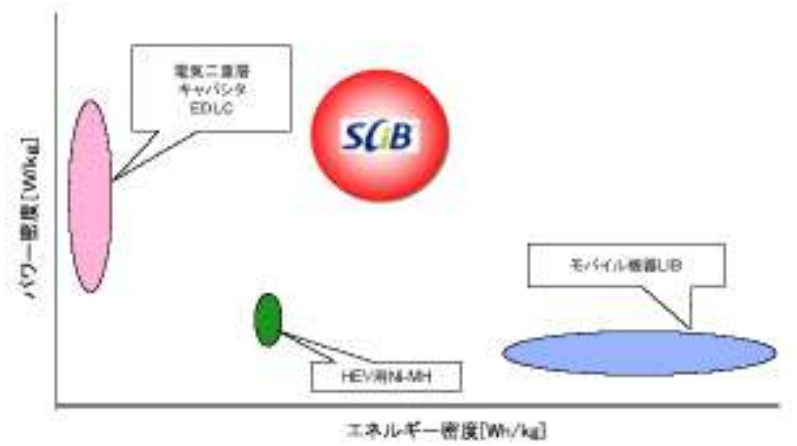

Fig.6. SCiB parameters compare with EDLC, $\mathrm{NiMH}$ and Li-Ion Accumulator

The SCiB (Fig.6) can bring the revolution due its fast charging and the long-lived efficiency, which exceeds 10 years, charge of $90 \%$ or more of capacity, possible boosting charge efficiency in only 5 minutes. Charging repetition, which exceeds 5000 times being possible, 10 years or more it can use over again with the charge of 1 day 1 time

A team of researchers at MIT is using nanotechnology to improve the storage capacity of capacitors [14]. Working with materials just a few atoms thick, they can build very complicated shapes with lots of surface area to hold electrical charge. Test show these devices can hold up to $50 \%$ of the energy a battery holds, and yet still maintain the advantages of quick release and easy recharge. The researchers predict this next generation of capacitors could someday help power electric cars or store energy from renewable sources.

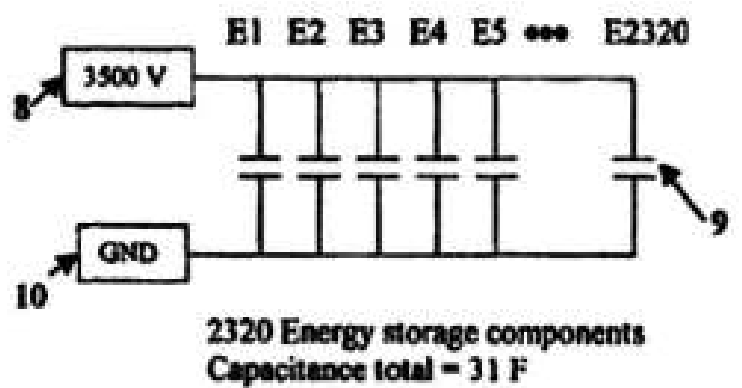

Fig.7. Parallel structure of EEStor SC

EEStor's patent (April 25, 2006) says [11], [12], it can safely charge the SC to 3500 volts and store at least 52,22 $\mathrm{kWh}$ of electrical energy. The motorist could plug in a car for five minutes and drive 500 miles.

The EEStor ESU (Energy Storage Unite) is projected to offer up to $10 \mathrm{x}$ the energy density (volumetric and gravimetric) of lead-acid batteries at the same cost. In addition, the ESU is projected to store up to 1,5 to 2,5 times the energy of Li-Ion batteries at 12 to $25 \%$ of the cost.
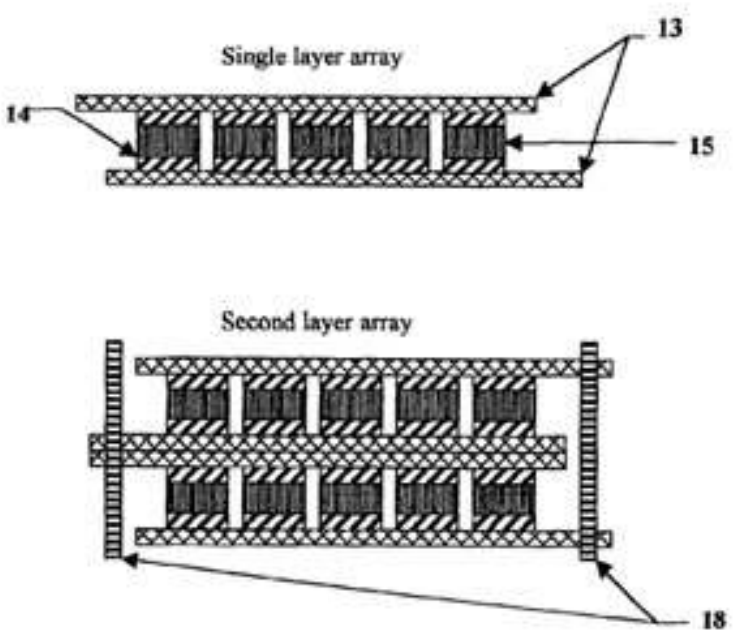

Fig.8. Multilayer structure of EEStor SC

The EEStor SC is quite different from the MIT LEES ultra-capacitor. The EEStor capacitor uses a barium titanate ceramic material as the dielectric. In a traditional 
$\mathrm{SC}$, that permittivity is given a rating of 20 to 30 , while EEStor's claim is 18500 or more--a phenomenal number by most accounts. Operating at 3500 volts is one of the keys to achieving high energy density with their design Fig.7. Their claimed energy density is $345 \mathrm{Wh} / \mathrm{kg}$ vs. $60 \mathrm{Wh} / \mathrm{kg}$ for the MIT cap.

The components are configured into a multilayer array (Fig.8) with the use of a solder-bump technique as the enabling technology so as to provide a parallel configuration of components that has the capability to store electrical energy in the range of $52 \mathrm{kWh}$. The total weight of an EESU with this range of electrical energy storage is about 336 pounds $(152 \mathrm{~kg})$, it can be charged in 3 to 6 minutes and retains charge with a loss rate of $0,1 \%$ per month.

\section{Conclusions}

The integration of third power source - super-capacitor in modern designed HEV with electrical transmission does not change considerably the main components parameters, because the motor and its controller are proposed to high maximal power overload, therefore only one bi-directional controller between the super-cap and DC bus must be inserted for a short term power peaks operation.

Only problem is the very low energy density value in upto-date SC, which causes not neglectable increase of total vehicle mass, but next parameter improvement is very sight. All the presented analyses are based on the actual state of the art and everything indicates the much better properties of both here analysed electric energy stores in the very near future when only the price gives the choice for each kind of vehicle.

\section{Acknowledgement}

The Czech Ministry of Education, Youth and Sport Financial Support, Program No OC169 for COST Action 542 , is acknowledged

\section{References}

[1.] http://www.toyota.com/prius/

[2.] http://automobiles.honda.com/civic-hybrid/

[3.] http://www.hybridcars.com/

[4.] http://www.chevrolet.com/electriccar/

[5.] http://www.gm-volt.com/

[6.] V. Bršlica: Battery Charging from Variable Speed Asynchronous Generator In WSEAS Transactions on Systems, Issue 8, Vol. 4, Corfu, Greece, August 2005 pp 1363-1367, ISSN 1109-2777

[7.] V. Bršlica: Co-generative Power Source for Electric Car In Proceeding of VPPC 2005 (CD-ROM), Chicago, IL, USA, Sept. 2005, Illinois Institute of Technology, IEEE Cat. No.: 05EX1117C, ISBN 0-7803-9281-7

[8.] http://www.ecom.cz/katalog pdf/maxwell.pdf

[9.] http://elektromobil.wz.cz/

[10.] T. Hund: Comparison Testing of Supercaps, Sandia National Laboratories, Albuquerque, NM, November 2004

[11.] United States Patent 7033 406,

[12.] http://www.freepatentsonline.com/7033406.html

[13.] http://www.toshiba.co.jp/about/press/2007 12/1102/SCiB .pdf

[14.] Joel Schindall: The Charge of the Ultra - Capacitors (Nanotechnology takes energy storage beyond batteries) http://www.spectrum.ieee.org/nov07/5636 , November 2007

[15.] Lockheed Martin Signs Agreement with EEStor, Inc., for Energy Storage Solutions, $10^{\text {th }}$ January 2008, http://www.gm-volt.com/2008/01/10/lockheed-martinsigns-agreement-with-eestor/ 